\title{
OBSERVATIONS ON THE TREATMENT OF PELLAGRA
}

\author{
BY TOM D. SPIES
}

(From the H. K. Cushing Laboratory of Experimental Medicine, Department of Medicine, Western Reserve University, and the Medical Service, Lakeside Hospital, Cleveland)

(Received for publication May 28, 1934)

\section{OBSERVATIONS ON THE TREATMENT OF PELLAGRA}

During the past few years great interest has centered in the etiology and treatment of pellagra. The disease was first recognized in 1735 by Casál (1), a Spanish physician, who believed that diet was a contributing factor in its development. Since that time, many theories $(2,3,4)$ have been advanced to explain its cause but at present only two of them are widely recognized: pellagra may be due to a bacterial infection (4), yet no specific bacterium has been discovered which is accepted by all as the causative agent; the disease, on the other hand, may be strictly a deficiency state (3) but no specific chemical substance has been isolated which prevents its development. It is well known, however, that many cases have been relieved by an adequate diet. On the other hand, many individuals in the advanced stages of the disease do not respond to such a diet while others are unable to take it at all. Likewise, many drugs, minerals, and food substances have been recommended as specific therapeutic agents $(3,5$, $6,7)$.

With the various theories of etiology and the diversity of recommended methods of treatment in mind, it seemed worthwhile to study pellagra in the hope that some additional information might be added to the present knowledge. This paper presents the results following the use of autoclaved yeast, ventriculin, and parenteral liver extract in a special clinic formed for the study of pellagra.

\section{SPECIAL STUDIES}

\section{A study of yeast as a therapeutic agent}

Goldberger and his associates $(3,12)$ showed that yeast, when added to a deficient diet, was efficacious in the prevention, and sometimes in the treatment of black tongue in dogs and pellagra in human beings. Later they concluded (3) from studies in prevention that both pellagra and blacktongue were due solely to the lack of vitamin $G$ (anti-dermatitis vitamin) which is the heat stable portion of the vitamin B complex. These investigators (14) also found that many of the common foods prevent the development of blacktongue and pellagra which they consider analogous. 
Since autoclaved yeast and many complex foods have been used as supplements to a deficient diet and apparently have protected against the development of pellagra, it was decided to place pellagrins on a diet of autoclaved yeast alone to determine whether it in itself might be used as a food capable of producing a remission of the disease.

Five classical cases of pellagra with involvement of the tongue and oral mucous membranes were chosen for this study. Each patient was given autoclaved yeast ${ }^{1}$ daily in amounts ranging from 250 to 500 grams, was allowed water ad libitum, and remained in bed throughout the course of the experiment.

All individuals in this group tolerated the diet of autoclaved yeast. At the end of the second day of the yeast therapy the mouth lesions were distinctly less red and swollen and by the fifth day they had practically disappeared. The patients by this time had ravenous appetites so they were given a high caloric, high vitamin diet. While these observations on the improvement of the oral lesions of five pellagrins restricted to a diet of yeast are in support of previous experiments by Goldberger and his associates (3) who found that supplements of yeast possessed preventive and therapeutic properties, in addition they show that yeast can be used as the sole source of food for pellagrins with rapid remission of the disease. Murlin and Mattill (13) have shown that yeast is an adequate food for human beings and contains such complex materials as proteins, fats, carbohydrates, minerals, and accessory food substances. Studies in this clinic (11) have shown that patients gain weight when they receive a diet consisting only of autoclaved yeast and water.

In view of the numerous recognized constituents of yeast and the variability of the disease, pellagra, any observation at this time must be interpreted with care before a conclusive statement can be justifiably made as to the nature of the substance in the yeast capable of producing therapeutic results. Some observers (12), however, consider the action of such a complex chemical substance as autoclaved yeast the same as that of a specific vitamin and designate this vitamin, $G$ or $B_{2}$. Goldberger and his associates $(3,12)$ have found that large amounts of many foods such as meat, milk, and eggs prevent the development of pellagra when added to a deficient diet and the present results indicate that autoclaved yeast in sufficient amounts can be used as the sole food and will cure the oral lesions of pellagra. Since all the known foods which result in the improvement of pellagrous lesions, including autoclaved yeast, are composed of many different materials, the chemical and physiological actions of which are little understood, it seems unwise at present to say unconditionally that the antipellagric factor is the heat stable substance or substances (vitamin G) which investigators have found so important in animal nutrition. Al-

1 Furnished through the courtesy of Dr. Isaac F. Harris, Harris Laboratories, Tuckahoe, N. Y. 
though Goldberger and his associates call this substance which protects against pellagra in each foodstuff, vitamin $G$, there is no proof that it is the same material in each food which is utilized by the body to prevent the disease.

Furthermore, it may well be that various materials are required to prevent such diverse manifestations of pellagra as gastro-intestinal lesions, involvement of the nervous system, and dermatitis. In a previous report (8) it was shown that striking improvement occurred in the skin lesions of five pellagrins, who were restricted to an unbalanced diet containing little of the so-called " vitamin G." This observation has been confirmed by Smith and Ruffin (9). As an explanation for the improvement, Wheeler (16) has suggested that a restricted diet forces a breakdown of the patient's body proteins which are subsequently used to cure the lesions but at the present time the information concerning the pathogenesis of pellagra is inadequate for a satisfactory evaluation of Wheeler's hypothesis.

\section{Ventriculin as a therapeutic agent}

For some years pellagra and pernicious anemia have been considered special types of deficiency diseases by some investigators. Each disease is characterized by remissions and relapses, glossitis, pyrexia, achylia gastrica, and at times central nervous system involvement, but despite these common signs and symptoms, the co-existence of the diseases has been observed rarely. Soon after Castle demonstrated the fundamental difference between the gastric juice of normal human beings and that of patients with Addisonian pernicious anemia (27), Sharp (17) and Sturgis and Isaacs (18) produced characteristic remissions of pernicious anemia by giving ventriculin, a defatted, dessicated substance prepared from pig's stomach, as Minot and Murphy (19) had been able to do with the oral administration of liver. In view of the fact that pellagra and pernicious anemia are two distinct clinical conditions with many similar signs and symptoms, it seemed worthwhile to determine whether ventriculin would cause remission in pellagra as it does in pernicious anemia.

Eight patients with the classical lesions of pellagra were selected for this determination. Each patient when admitted to the hospital was offered-but not forced to eat-the unbalanced diet low in so-called " vitamin G," shown in Table I. This diet resembles one of Goldberger and Wheeler's more than any of the other deficient diets.

After a period of from two to ten days the glossitis and stomatitis became more severe. At this time ventriculin ${ }^{2}$ in amounts of 750 to 1000 grams per day was added to the basal diet of each of five patients and no other food was allowed. Three other patients were given the ventriculin but the basic diet was discontinued.

${ }^{2}$ Furnished through the courtesy of Dr. E. A. Sharp, Parke, Davis \& Co. 


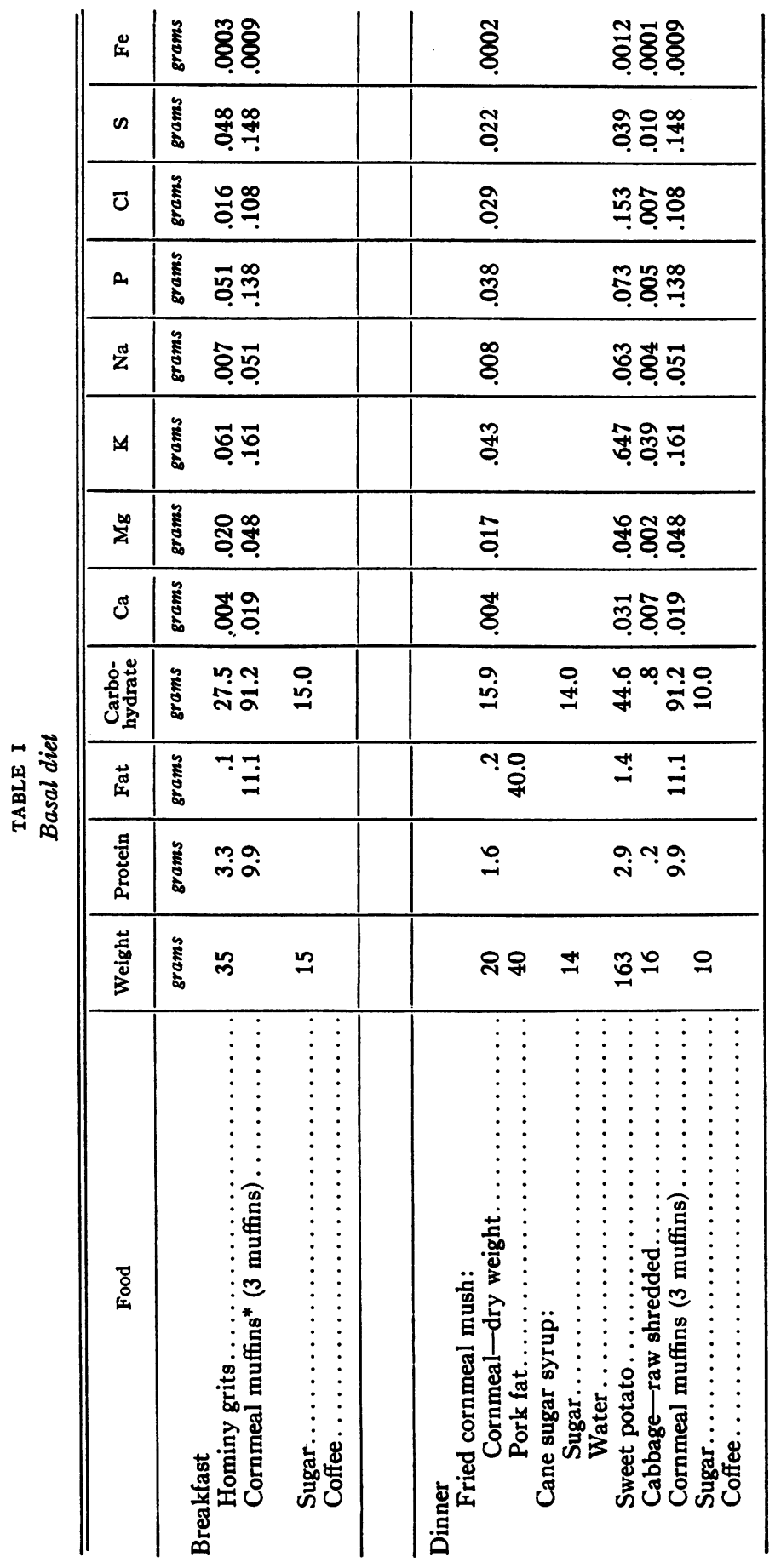




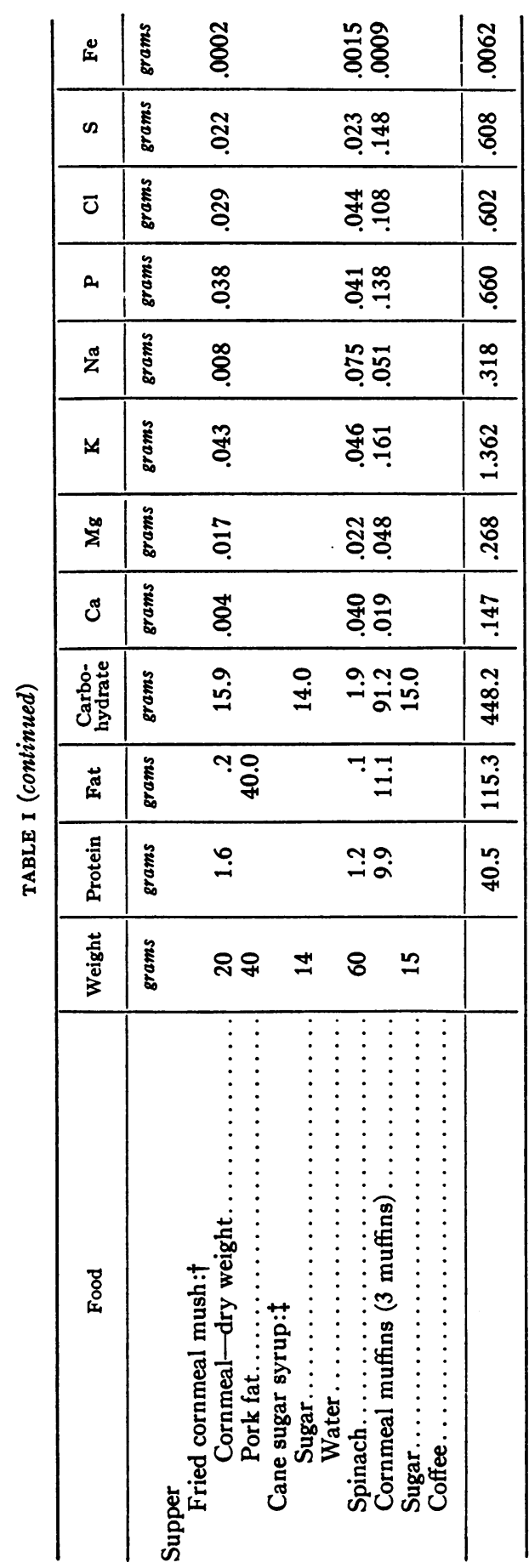

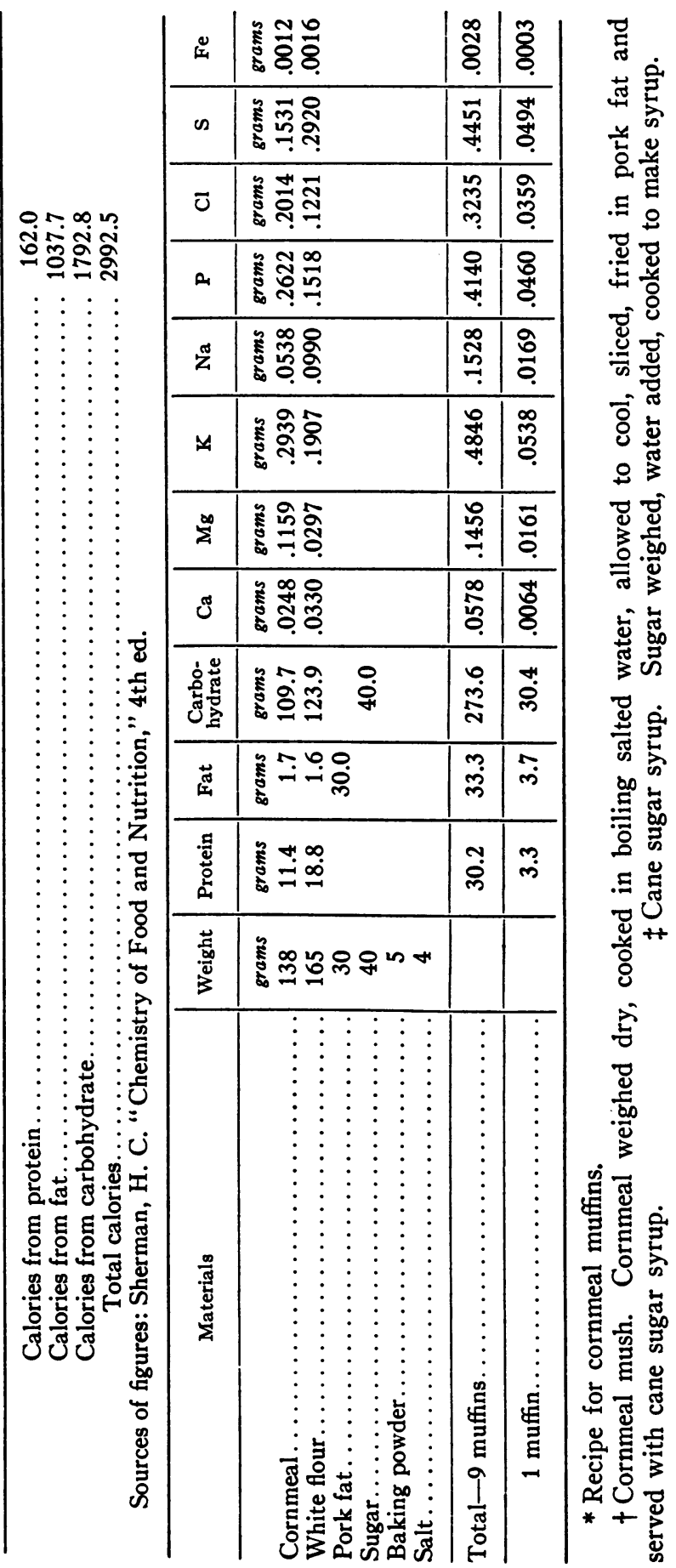


Each patient began to improve within twelve to twenty-four hours after the first administration of ventriculin and the glossitis and stomatitis, which had become worse on the basic diet, healed so rapidly that within seventy-two hours from the beginning of the administration of ventriculin, the oral lesions had disappeared. It was noteworthy that the patient's desire for food increased soon after the ventriculin was given. Since none of these patients had the neurological manifestations of pellagra, the therapeutic effect of ventriculin on the central nervous system involvement could not be determined. The skin lesions had begun to improve on the basic diet (an observation which has been pointed out previously (8)) before ventriculin treatment was initiated so it was impossible to determine whether or not ventriculin aided in healing them under these conditions.

Since ventriculin is efficacious in the treatment of pernicious anemia and pellagra and since both conditions have certain clinical similarities, one speculates as to whether or not the same substance in ventriculin cures both diseases. Castle (27) believes that pernicious anemia is a condition secondary to a lack of some unknown constituent in the patient's gastric juice. Spies and Payne (20) incubated the gastric juice of two acute pellagrins receiving a vitamin G-free diet (glucose and lactose) with beef and found that the mixture contained an antianemic substance capable of producing a remission in pernicious anemia. They suggested that, in the pathogenesis of the two conditions, the usual pellagrin develops his disease following inadequate ingestion of food and that the pernicious anemia patient has a predisposing gastric dysfunction which prevents the proper assimilation of his food.

Ventriculin must be regarded as a very complex substance. It cures or prevents the manifestations of vitamin $G$ deficiency in white rats and prevents the development of anemia in dogs receiving a pellagra-producing diet over a long period of time $(21,22)$. It must be realized, furthermore, that the knowledge of pellagra and pernicious anemia is far from complete and, though there may be some possible relationship in the pathogenesis of the two conditions, speculation at this time is not justifiable. This is particularly pertinent in that the chemical nature of the antianemic and antipellagric factors is not yet understood.

\section{Parenteral liver extract as an aid in treatment}

A short time ago Goldberger and Sebrell (23) found that liver extract fed to dogs in large amounts either prevented or retarded the development of black tongue. Boggs and Padget (7) stressed the curative value of liver (not liver extract) in pellagra and Smith and Ruffin (9) and Spies (8) have found that large amounts of liver extract by mouth are efficacious in treating the disease. Ramsdell and Magness (24), in a preliminary study on the effects of intramuscular liver extract on the course of pellagrins, gave small ( $2 \mathrm{cc}$.) daily doses and at the same time allowed pa- 
tients a highly nutritious diet. They felt that the intramuscular administration of liver extract resulted in clinical improvement, but were frank to state that the patients were not given a deficient diet. Recently Ruffin and Smith (28) under more carefully controlled conditions observed no therapeutic effect when $5 \mathrm{cc}$. of parenteral liver extract were given. It has been recognized for a long time that the high mortality rate in severe pellagra is usually the result of central nervous system involvement, pernicious vomiting or an intractable diarrhea. As might be expected, many of these patients either refuse food or are unable to assimilate or absorb it and the disease progresses until death. Since the mortality rate is so high in the severely diseased pellagrin ( 54 to 69 per cent), it was decided to determine under controlled conditions whether or not parenteral liver extract is a valuable therapeutic agent capable of reducing the mortality rate of the disease.

Sixteen patients with the classical skin and oral lesions of pellagra were selected for this method of treatment. The results following the treatment of some of these patients have been reported in a preliminary communication (29). Each patient was placed on the unbalanced diet, low in socalled "vitamin G," at the time of admission and was not urged to eat more than he chose. After the stomatitis and glossitis had become definitely worse in each instance, $80 \mathrm{cc}$. of liver extract ${ }^{3}$ were administered intravenously in four doses to each of ten patients during the subsequent twenty hours. This treatment was followed by the healing of the oral lesions after which no further injections of liver extract were given. Seven of the ten were then given a well balanced diet. The remaining three were still offered the basic diet until each patient relapsed and had a recurrence of mild but definite oral lesions of pellagra. Again these patients were given liver extract in the same manner as described before and the pellagrous condition subsided. Each of the remaining six of the sixteen pellagrins was given three intramuscular injections of liver extract totaling from $24 \mathrm{cc}$. to $30 \mathrm{cc}$. within a period of thirty hours.

No untoward reactions occurred from the intravenous or intramuscular injections of liver extract and twelve to twenty-four hours later the patients were improved. In each instance the tongue and oral mucous membranes, which had become progressively worse on the basic diet, appeared less red and swollen within twenty-four hours after the first injection. Seventy-two hours after the liver therapy the lesions had healed and were grayish pink in color instead of the fiery red observed prior to treatment. The three patients who remained on the restricted diet again developed lesions of the tongue and mucous membranes within ten days, but dermatitis did not reappear during this short time. These relapses were likewise successfully treated by means of intravenous liver extract.

\footnotetext{
${ }^{3}$ Furnished through the courtesy of Dr. E. A. Sharp, Parke, Davis \& Co.
} 
The patient's desire for food increased following this therapy. In these patients the skin lesions improved rapidly. Under the conditions of this experiment, the changes in the dermatitis cannot be attributed to a specific action of liver extract. Since the patients in this study had no mental symptoms, the effect of parenteral liver extract on neurological manifestations could not be determined.

The present study has demonstrated that either the intravenous or the intramuscular administration of large amounts of potent liver extract causes a remission of the oral manifestations of pellagra. It has been previously pointed out (10) that the oral lesions, and not the dermatological ones, should be used for prognosis and the testing of materials for therapeutic efficacy. It is already known that an adequate diet usually prevents the development of pellagra and oftentimes cures it when it has begun (3), but the mortality rate in institutions admitting severe pellagrins is from fifty-four (25) to sixty-nine (7) per cent, even when the patients are offered a highly nutritious diet. It was realized some time ago that this high mortality rate was due in part to the patient's inability to eat and therefore efforts were made to develop a parenteral therapeutic agent (26). While an adequate diet is usually curative for patients with mild pellagra, it seems on theoretical grounds that their convalescence might be shortened by either intravenous or intramuscular injections of potent liver extract. It should be especially useful as an aid in treating the severe pellagrins who cannot or will not eat sufficient quantities of food.

\section{SUMMARY AND CONCLUSIONS}

1. It has been shown in the present experiments that the oral lesions of pellagra heal rapidly while the patient's diet is restricted to large amounts of either autoclaved yeast or ventriculin.

2. These findings suggest that there may be some etiological relationship between pellagra and pernicious anemia.

3. The evidence is too meager at the present time to justify the designation of vitamin $\mathrm{G}$ as the specific substance capable of curing pellagra.

4. It has also been shown in the present experiment that the oral manifestations of sixteen pellagrins responded dramatically following the parenteral administration of massive doses of liver extract.

5. The use of large doses of liver extract is suggested, either intravenously or intramuscularly whenever a severe pellagrin has difficulty in ingesting or assimilating sufficient quantities of a highly nutritious diet.

\section{BIBLIOGRAPHY}

1. Casál, D. G., Historia natural y medica de el Principado de Asturias, Obra posthuma del Doctor D. G. Casál, Medico de Su Magestad y su Protomedico de Castilla, Madrid, 1762. 
2. Goldberger, J., and Wheeler, G. A., Experimental production of pellagra in human beings by means of diet. Hygienic Laboratory, Washington, Bulletin 120, Feb. 7, 1920.

3. Goldberger, J., Wheeler, G. A., Lillie, R. D., and Rogers, L. M., A further study of butter, fresh beef and yeast as pellagra preventives with consideration of the relation of factor P-P of pellagra (and black tongue of dogs) to vitamin B. U. S. Pub. Health Reports, 1926, 41, 297.

4. Siler, J. F., Garrison, P. E., and MacNeal, W. J., Further studies of the Thompson-McFadden pellagra commission: A summary of the second progress report. J. A. M. A., 1914, 63, 1090.

5. Niles, G. M., A discussion of the therapy of pellagra. Med. J. and Rec., $1927,125,513$.

6. Wilson, J. F., Arsphenamin in pellagra: Report of 100 cases. Paper read before Section on Dermatology and Syphylology of Southern Medical Association, Miami, Nov. 22, 1929.

7. Boggs, T. R., and Padget, P., Pellagra : Analysis of 102 cases. Bull. Johns Hopkins Hosp., 1932, 50, 21.

8. Spies, T. D., Pellagra: Improvement while taking so-called "Pellagra-producing diet." Am. J. M. Sc., 1932, 184, 837.

9. Smith, D. T., and Ruffin, J. M., Treatment of pellagra with liver extracts. J. Clin. Invest., 1933, 12, 963.

10. Spies, T. D., Pellagra: An experimental study of the skin lesions. Arch. Int. Med., 1933, 52, 945.

11. Spies, T. D., Unpublished observations.

12. Goldberger, J., Wheeler, G. A., Lillie, R. D., and Rogers, L. M., A further study of experimental black tongue with special reference to the black tongue preventive in yeast. U. S. Pub. Health Rep., 1928, 43, 657.

13. Murlin, J. R., and Mattill, H. A., The laxative action of yeast. Am. J. Physiol., 1923, 64, 75.

14. Goldberger, J., and Lillie, R. D., A note on an experimental pellagra-like condition in the albino rat. U. S. Pub. Health Rep., 1926, 41, 1025.

15. Goldberger, J., and Wheeler, G. A., Experimental black tongue of dogs and its relation to pellagra. U. S. Pub. Health Rep., 1929, 43, 172.

16. Wheeler, G. A., Pellagra, Nelson Loose-Leaf Medicine (Service Volume), 1932, 238.

17. Sharp, E. A., An antianemic factor in dessicated stomach. J. A. M. A., $1929,93,749$.

18. Sturgis, C. C., and Isaacs, R., Dessicated stomach in the treatment of pernicious anemia. J. A. M. A., 1929, 93, 747.

19. Minot, G. R., Murphy, W. P., and Stetson, R. P., The response of the reticulocytes to liver therapy: Particularly in pernicious anemia. Am. J. M. Sc., 1928, 175, 581.

20. Spies, T. D., and Payne, W., A study of the etiological relationship between pellagra and pernicious anemia. J. Clin. Invest., 1933, 12, 229.

21. Spies, T. D., and Grant, J., An experimental study of a so-called "Pellagraproducing" diet. Am. J. Physiol., 1933, 104, 18.

22. Spies, T. D., Dowling, A. S., and Chinn, A. B., Unpublished observations.

23. Goldberger, J., and Sebrell, W. H., The black tongue preventive value of Minot's liver extract. U. S. Pub. Health Rep., 1930, 45, 3064.

24. Ramsdell, R. L., and Magness, W. H., Parenteral liver extract therapy in the treatment of pellagra. A preliminary report. Am. J. M. Sc., 1933, 185, 568. 
25. Spies, T. D., and DeWolf, H. F., Observations on the etiological relationship of severe alcoholism to pellagra. Am. J. M. Sc., 1933, 186, 521.

26. Spies, T. D., Intravenous administrations of wheat germ to patients with pellagra. Proc. Soc. Exper. Biol. and Med., 1933, 30, 850.

27. Castle, W. B., Heath, C. W., and Strauss, M. B., Observations on the etiologic relationship of achylia gastrica to pernicious anemia. IV. A biologic assay of the gastric secretion of patients with pernicious anemia having free hydrochloric acid and that of patients without anemia or with hypochronic anemia having no free hydrochloric acid, and of the rôle of intestinal impermeability to hematopoietic substances in pernicious anemia. Am. J. M. Sc., 1931, 182, 741.

28. Ruffin, J. M., and Smith, D. T., The treatment of pellagra with certain preparations of liver. Am. J. M. Sc., 1934, 187, 512.

29. Spies, T. D., Treatment of pellagra by means of parenteral liver extract. Proc. Soc. Exper. Biol. and Med., 1933, 31, 363. 